\title{
High sensitivity cardiac troponin and the under-diagnosis of myocardial infarction in women: prospective cohort study
}

\author{
(@) $(1) \Theta$ OPEN ACCESS
}

This Research article (BMJ 2015;350:g7873, doi:10.1136/bmj. g7873) was mistakenly published under the CC BY NC licence

should have been published under the CC BY licence. The initially online and in the March 2015 academic print issue, and

online version has since been corrected. 